\title{
Nitrogen monoxide and oxidative stress: composition and intensity of cellular oxidative bursts cocktail. A study through artificial electrochemical synapses on single human fibroblasts
}

\author{
C. Amatore,* S. Arbault, D. Bruce, P. de Oliveira, M. Erard, N. Sojic ${ }^{1}$ and M. Vuillaume \\ École Normale Supérieure, Département de Chimie, UMR CNRS 8640 “PASTEUR”, 24, rue Lhomond, 75231 Paris Cedex 05, France \\ ${ }^{1}$ Present address: LACREM, ENSCPB, B.P. 108, 33402 Talence Cedex, France \\ * Corresponding author: amatore@ens.fr
}

\begin{abstract}
Positioning an ultramicroelectrode at micrometric distances from an isolated living cell ensures that any electroactive material released by the cell is collected and analyzed by the electrode surface. The film of extracellular fluid comprised between the cell and the electrode surfaces defines an artificial synaptic cleft of a few hundred femtoliters volume, in which the release of minute molecular amounts of chemicals produces a sudden and important concentration rise. This guarantees the detection of the released species with an extremely high signalto-noise ratio, as well as a determination of its instant released flux since the collection efficiency is quantitative. In other words, the assembly cell/liquid cleft/ultramicroelectrode behaves as an artificial neuronal synapse. In this review we wish to elaborate on how this artificial synaptic arrangement may be used to monitor an oxidative stress response stimulated in a human fibroblast, and demonstrate that such long-time conjectured oxidative cellular bursts involve a subtle cocktail of femtomoles of hydrogen peroxide, nitrogen monoxide, peroxynitrite and nitrite ions. The analysis performed establishes that this delicate cocktail results from the ultimate combinations of equimolar primary productions of superoxide ion and nitrogen monoxide by two distinct enzymatic systems which are presumably operating in distinct compartments of the cell: NADPH-oxidase type enzymes for the generation of superoxide, and NO-synthases for that of nitrogen monoxide.
\end{abstract}

\section{Introduction: principle of artificial electrochemical synapses}

The analytical and kinetic investigation of infinitely minute amounts of molecules released by a living cell outside its cytoplasm during a brief fraction of time (i.e., milliseconds to seconds) represents a considerable modern analytical challenge [1,2]. Indeed, on the one hand, the amount released (viz., generally between zeptomoles and femtomoles) is infinitely small by general analytical standards, and on the other hand, the whole event is completed within a very short time. Both factors emphasize the huge difficulty of the analytical detection in terms of signal-to-noise ratio, and explain easily why the study of secretion events has been seldom investigated by biologists at the single cell level despite their extreme biological importance in cellular metabolic activity including defense and communication mechanisms [1-6].

The quality of any analytical information requires a sufficient signal-to-noise ratio. Taking for granted that the analytical device has been selected to perform adequately, both thermodynamically and kinetically, a sufficient signal-tonoise ratio requires only a sufficient concentration of the chemical to be detected. It is important to stress here that a large concentration does not mean at all a large quantity since a concentration is a quantity of chemicals divided by a volume sampling size. Thus, an infinitely small number of molecules may be easily converted into a large concentration by restricting the volume in which these molecules are released. This is the simple arithmetic solution retained by Nature in its biological synapses, so as to detect with a high signal-to-noise ratio the release of zepto- to attomoles of chemical messengers during extremely minute durations [1-5].

This solution may easily be adapted to electroanalytical purposes [1-6]. Indeed, whenever the released molecules are electroactive and identifiable electrochemically, placing an electrode at micrometric or sub-micrometric distances from a living cell ensures an adequate signal-to-noise ratio by restricting the extracellular volume in which the molecules emitted by the cell are released. For example, one femtomole delivered in a volume of a thousand $\mu \mathrm{m}^{3}$ creates a millimolar concentration rise, i.e., produces a concentration variation which can be monitored electrochemically with an excellent signal-to-noise ratio provided that the electrode does not pick up too much noise through its surface. 
(a)

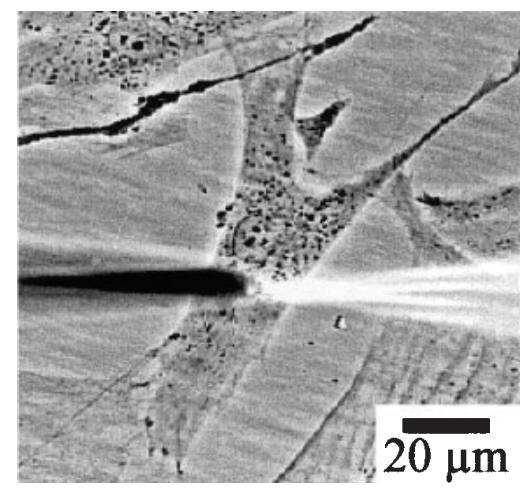

(b)

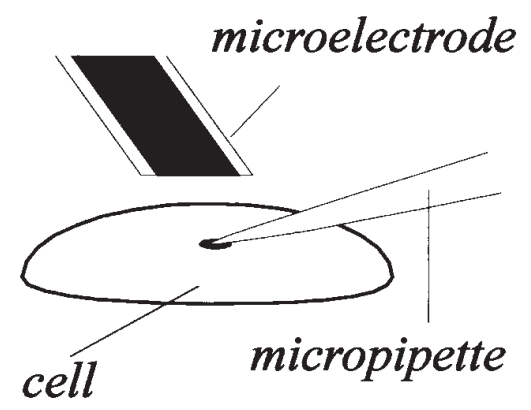

(c)

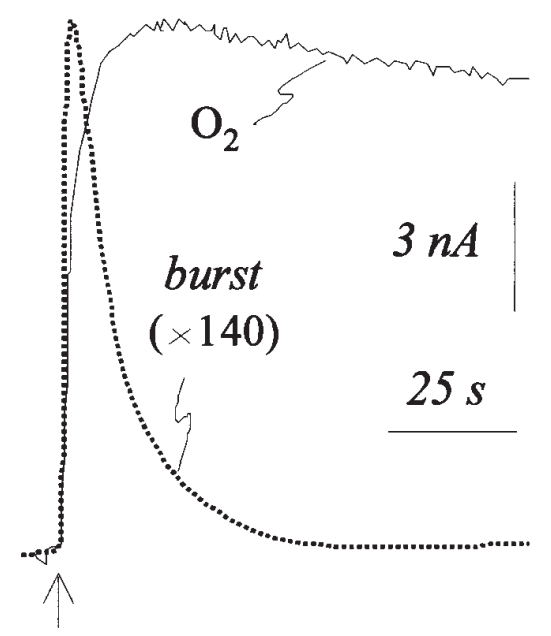

Figure 1. (a) View of a human fibroblast on a Petri dish bottom indicating the positioning of the ultramicroelectrode (black shadow) and of the micropipette (white shadow) used to stimulate the oxidative burst. Note that these objects, being in a slanted position above the fibroblast, are out of focus. (b) Schematic representation of the artificial synaptic configuration used in this study (see text). (c) Current traces detected at 0.450 (dotted curve A) or -0.250 (solid curve B) V vs. SSCE as a function of time after the stimulation of a human fibroblast by the micropipette (arrow), when the electrode (10 $\mu \mathrm{m}$ radius) is positioned at $h=50 \mu \mathrm{m}$ above the cell. Note that the two baselines have been shifted to be coincident before the stimulation. However, in A the current measured after the stimulation is anodic (oxidative burst), while in B it remains cathodic and evidences a decrease of the oxygen concentration in the near environment of the cell.
Electrodes pick up electrical noise through their capacitance, viz., through their overall conducting surface area, while the analytical information (viz., the Faradaic current) may arise only from the surface area exposed to the cell release. Thus, using an electrode with an active surface matching that of the examined cell decreases the noise while it does not affect at all the quality and intensity of the analytical information. This increases the signal-to-noise ratio and ensures simultaneously a quantitative collection efficiency since the artificial synaptic cleft covers the cell emitting surface. Cells being of micrometric dimensions, it is understood that positioning an ultramicroelectrode at micrometric distances from an isolated living cell (Fig. 1 a,b) ensures the most adequate signal-to-noise ratio and guarantees that the collection of electroactive chemicals released by a single living cell surface is total [1-6]

\section{Application of artificial synapses to oxidative stress}

\section{The biological problem and its biological and medical importance}

Aerobic cells are known to produce superoxide ion $\left(\mathrm{O}_{2}^{-}\right)$and nitrogen monoxide (NO) in response to a stress created by a drastic change in the cell activity provoked by an aggression of its membrane integrity (during a viral or bacterial intrusion for example) or following a sudden and drastic change in its surrounding medium. The released NO is thought to originate from the activation of cell NO-synthases (eq. 1) [7]:

$$
\begin{aligned}
& L \text {-arginine }+2 \mathrm{NADPH}+2 \mathrm{O}_{2}+2 \mathrm{H}^{+} \\
& \mathrm{NO}+\text { citrulline }+2 \mathrm{NADP}^{+}+2 \mathrm{H}_{2} \mathrm{O}
\end{aligned}
$$

There is thus a considerable analytical effort to monitor its concentration changes in living tissues or body-fluid circulations, to monitor the occurrence of a stress for example during a surgical operation. However, development of such specific and sensitive sensors is not our purpose here.

Superoxide is constantly produced as an unwanted side product (ca., 6-8 \% of metabolic oxygen) during the normal metabolism of aerobic cells [8-18]. Most of this hazardous species is readily scavenged through its fast disproportionation into hydrogen peroxide and oxygen (eq. 2-4):

$$
\begin{gathered}
\mathrm{O}_{2}^{-}+\mathrm{H}^{+} \longrightarrow \mathrm{HOO}^{\bullet} \quad\left(K_{\mathrm{pH} 7} \ll 1\right) \\
\mathrm{HOO}^{\bullet}+\mathrm{O}_{2}^{-} \longrightarrow \mathrm{HOO}^{-}+\mathrm{O}_{2} \quad \text { (fast) } \\
\mathrm{HOO}^{-}+\mathrm{H}^{+} \longrightarrow \mathrm{H}_{2} \mathrm{O}_{2} \quad \text { (fast) }
\end{gathered}
$$

which is catalyzed by superoxide dismutase $(S O D)$ in living aerobic cells (eq. 5):

$$
2 \mathrm{O}_{2}^{-}\left(+2 \mathrm{H}^{+}\right) \longrightarrow \mathrm{H}_{2} \mathrm{O}_{2}+\mathrm{O}_{2}
$$

However, $\mathrm{H}_{2} \mathrm{O}_{2}$ is a much more potent cytotoxic chemical since its life-time is sufficient to allow its diffusion to almost any cellular compartment, where it may act as a potential 
source of hydroxyl radicals through the Fenton reaction [818]. Hydroxyl radicals being among the best hydrogen atom acceptors, they are prone to induce a large variety of biological mutations. If generated within the membrane of a cell, they provoke a fast disruption of the cellular membrane cohesion via radical catalyzed peroxidation of cell bilipids through the Haber-Weiss reaction.

In living cells, $\mathrm{H}_{2} \mathrm{O}_{2}$ is scavenged by catalase which catalyzes its fast disproportionation into oxygen and water so that its concentration is maintained at nanomolar steady state levels and the above lethal routes are thus prevented [8-18]. In spite of its considerable efficiency at the nanomolar and sub-nanomolar physiological concentrations of hydrogen peroxide, catalase is inhibited by its substrate at higher concentrations. Thus, aerobic cells are unprotected by catalase against $\mathrm{H}_{2} \mathrm{O}_{2}$ whenever its concentration rises significantly beyond normal physiological levels. A sudden increase of $\mathrm{H}_{2} \mathrm{O}_{2}$ concentration stimulates the proteic expression of higher concentrations of scavengers suited to perform efficiently in these higher concentration ranges, but this requires at least half an hour [19-22].

There are several indications that this defect in the catalytic " $\mathrm{H}_{2} \mathrm{O}_{2}$-armor" may in fact be used by some cells like fibroblasts against possible intruders (bacteria, viruses, etc.). Indeed, a cell may change its normal oxygen metabolism so as to produce important quantities of superoxide through the involvement of its NADPH oxidase type enzymes (eq. 6) [23-25].

$$
2 \mathrm{O}_{2}+\mathrm{NADPH} \longrightarrow 2 \mathrm{O}_{2}^{-}+\mathrm{NADP}^{+}+\mathrm{H}^{+}
$$

It is also suspected that this metabolic change is associated to the production of other "ROS", or "reactive oxygen species" as improperly coined by biologists, which are thought to include nitrogen monoxide (through activation of $\mathrm{NO}$-synthases, eq. 1) and maybe peroxynitrite $\left(\mathrm{ONO}_{2}^{-}\right)$as well. Indeed, superoxide and NO couple at a rate close to the diffusion limit $\left(\sim 2 \times 10^{10} \mathrm{M}^{-1} \mathrm{~s}^{-1}\right.$, eq. 7) [26]:

$$
\mathrm{O}_{2}^{-}+\mathrm{NO} \longrightarrow \mathrm{ONO}_{2}^{-}
$$

At physiological $\mathrm{pH}$, peroxynitrite may decompose through the intermediate formation of its conjugated acid $\mathrm{ONOOH}$ $\left(\mathrm{pK}_{\mathrm{a}} \approx 6.8[26]\right)$. Peroxynitrite is expected to protonate partially in the extracellular fluid while it diffuses away from the cell:

$$
\mathrm{ONO}_{2}^{-}+\mathrm{H}_{3} \mathrm{O}^{+} \rightleftharpoons \mathrm{ONOOH}+\mathrm{H}_{2} \mathrm{O}
$$

ONOOH undergoes two facile decomposition routes. At physiologically normal peroxynitrite concentrations, the most efficient one is reported to proceed through its overall pseudo first-order cleavage into proton and nitrate ion $\left(k_{9}=0.2 \mathrm{~s}^{-1}\right.$, eq. 9) [26]:

$$
\mathrm{ONOOH} \longrightarrow \mathrm{H}^{+}+\mathrm{NO}_{3}^{-}
$$

$\mathrm{ONOOH}$ decomposition into nitrite ions may also occur through an overall second-order process related to the spontaneous evolution of its 1:1 complex with peroxynitrite (eq. 10-11) [26]:

$$
\begin{gathered}
\mathrm{ONOOH}+\mathrm{ONO}_{2}^{-} \rightleftharpoons \mathrm{C} \\
\mathrm{C} \longrightarrow 2 \mathrm{NO}_{2}^{-}+\mathrm{O}_{2}+\mathrm{H}^{+}
\end{gathered}
$$

This second route is reported to be slower than the first one under normal physiological concentrations [26], but owing to its second order nature it may become predominant whenever peroxynitrite concentrations exceed physiological normal ones. Anyway, both reactions are certainly too slow [26] to deplete a concentration wave of peroxynitrite while it diffuses over a few micrometers away from the cell since this requires only a few tens of milliseconds (vide infra). Conversely, peroxynitrite should not survive much larger diffusional distances requiring several seconds.

Similarly, when diffusing over significant distances from its source, NO is expected to react significantly with oxygen $\left(k=2 \times 10^{6} \mathrm{M}^{-2} \mathrm{~s}^{-1}\right)$ since this species is present at rather important concentrations $(0.24 \mathrm{mM})$ in the aerated extracellular fluid [27]:

$$
4 \mathrm{NO}+\mathrm{O}_{2}+2 \mathrm{H}_{2} \mathrm{O} \longrightarrow 4 \mathrm{NO}_{2}^{-}+4 \mathrm{H}^{+}
$$

The existence of such a series of complex and intricately interconnected pathways which ought to follow any simultaneous production of superoxide and nitrogen monoxide by living cells explains why the very nature of the ROS species has not been fully characterized yet. However, and although their exact nature has not been completely identified so far, $R O S$ are known to be involved in apoptosis, the suicidal ordered rapid death of cells [28]. Moreover, based on clinical observations and on the investigation of patient metabolites, deregulations of $R O S$ production seem to be involved (directly or indirectly through apoptosis) in several human pathologies (ageing, cancers, Parkinson and Alzheimer diseases, auto-immune pathologies, arthritis, etc. [19]) and have been shown more recently to play a crucial role in $\mathrm{T}$ cell depletion in AIDS pathogenesis [29-32].

This existence of ROS fast production (termed oxidative stress or oxidative burst) has thus been recognized and longterm effects have been extensively investigated by biologists and physicans based upon the observation of cell metabolites (days to years) or upon its effects on cellular activation mechanisms (hours, days). However, despite their apparent ubiquity and importance in aerobic cells, there was almost no indication about the intensity or duration of the primary oxidative bursts, nor even on the true nature of the chemical species shyly covered by the ROS mysterious acronym.

In this review, we wish therefore to summarize the results achieved so far in our laboratory through precise electroanalytical investigations of the nature, intensity and kinetics of oxidative stress [32-35]. To complete and strengthen this view, we wish also to include some recent data on the effect of inhibitors which have not been reported so far [36]. 


\section{Monitoring electrochemically a single-cell oxidative burst}

Oxidative stresses induced in human fibroblasts (used as models of skin carcinogenesis in our studies [33,35]) and human lymphocytes (used as models of HIV infection in our studies [28,32,34]) may be investigated electrochemically through the artificial synaptic method described above (Fig. 1 a,b). In the following, we restrict our presentation to fibroblasts. The electrodes consisted of carbon disks of ca. $10 \mu \mathrm{m}$ radius obtained from the cross-section of a carbon fiber sealed into a thin soft glass case [2,33]. The exposed carbon disk was beveled and polished, and platinized so as to increase its electrochemical activity towards small oxygen-containing molecules expected to be released in oxidative bursts (vide supra). The electrode was placed in the desired position with a micromanipulator under optical microscopy control [33].

Oxidative bursts were stimulated by the fast pricking of the cell membrane with a sealed patch-clamp micropipette (ca. $1 \mu \mathrm{m}$ radius) moved with a second micromanipulator [33]. This method was checked to produce no lethal damages to the examined cells. In fact, its more drastic consequences ought to be lesser than those made during nowadays common biological experiments involving the direct delivery of biochemical or genetic materials into cells inner compartments through identical micropipettes. The oxidative stress response is presumably stimulated by the instant depolarization of the membrane provoked by the rapid interconnection of the two different double layers built up on each face of the cell membrane.

Since fibroblasts need to be examined in a biologically compatible environment (air saturated PBS in a Petri dish at $\left.25^{\circ} \mathrm{C}\right)$ they are necessarily surrounded by a large $(0.24 \mathrm{mM})$ concentration of oxygen. The presence of the highly reducible oxygen molecule at such a high concentration forbids any exploration of too cathodic potential ranges, so the analytical detection and identification of species released by the cell have to be performed far from the very foot of the oxygen reduction wave, i.e., at potentials larger than $0.275 \mathrm{~V}$ vs. SSCE [35]. This unfortunate electroanalytical limitation is however essential from the point of view of the precision of the analytical detection. This difficulty is stressed in figure 1c [33] which compares the traces obtained at $-0.25 \mathrm{~V} v s$. SSCE (evidencing a considerable decrease in the oxygen reduction current due to its fast important consumption by the cell following the onset of the oxidative burst) or at $+0.450 \mathrm{~V} v s$. SSCE (showing a comparatively much smaller - i.e., ca. 150-fold lesser - increase of the oxidation current due to the fast production of $R O S$ during oxidative bursts).

This limitation is even more essential from the point of view of the accuracy and of the biological significance of the results. Exploring a potential range negative to ca. $0.275 \mathrm{~V}$ vs. SSCE [35] amounts to affect extremely significantly the cell whenever the electrode is close to it. Indeed, on the one hand, the electrochemical consumption of oxygen in the vicinity of the cell would create an anaerobic stress and induce several biological consequences. On the other hand, since the primary product of oxygen electrochemical reduction is superoxide, the cell would be blasted by huge concentrations (viz., comparable to $0.24 \mathrm{mM}$, that of oxygen) of superoxide and hydrogen peroxide (eq. 2-4). All these undesirable effects are prevented when the potential range examined is restricted to any values above $0.275 \mathrm{~V} v s$. SSCE whenever the electrode is close to the cell (i.e., within micrometers) or when, as in the experiments shown in figure $1 \mathrm{c}$, the electrode is far away from the cell [33]. However, in this second situation, collection efficiencies are small, and moreover several shortlived species may not survive the several seconds-long diffusional flights required to reach the electrode surface (vide infra).

Because of the dendritic platinization required to obtain decent electrochemical responses [33], the ultramicroelectrode capacitances are excessively large and so are capacitive currents. On the other hand, pricking the cell membrane creates a connection between its cytosol and the extracellular fluid where the electrode is positioned. This induces important diffusional fluxes of non-electroactive ions towards the electrode surface. Thus, double layer capacitances and therefore capacitive currents are expected to vary significantly following the membrane intrusion. Both features prevent the use of transient methods such as chronoamperometry or even moderately fast cyclic voltammetry (viz., ca. $\left.50-100 \mathrm{Vs}^{-1}\right)[1,2]$ to investigate the nature of the products released by the cell during oxidative bursts. Slow voltammetric scans (viz., at scan rates of a few volts per second or less) would be compatible since the capacitive currents would be small enough, but they cannot be used here because the potential scan durations would be comparable to the signal half-widths (compare Fig. 2).

Because of all the above intrinsic constraints borne by the specific nature of the phenomenon investigated, the electrochemical detection and analysis of oxidative bursts need to be carried out at constant potentials above $0.275 \mathrm{~V}$ $v s$. SSCE. Any electrochemical analysis of oxidative bursts requires then a series of independent measurements performed at different potentials. Such collections of independent measurements are necessarily obtained from a series of different cells, viz., one cell per potential investigated.

This built-in requirement introduces another great difficulty which is among the largest ones in any bioelectrochemical investigation involving isolated living cells. Indeed, by essence, cell responses exhibit a strong variability. Thus, the parameters featuring two events recorded at two different cells cannot be directly compared even when performed under identical conditions. Any comparison of responses obtained at different potentials thus requires that a statistically significant population of cells is investigated at each potential so that a statistical analysis may be performed. In our experiments, this necessitated the averaging of 25-40 individual cell responses at a given electrode potential depending on the cell culture examined. Then, the standard deviations were small enough for observing 


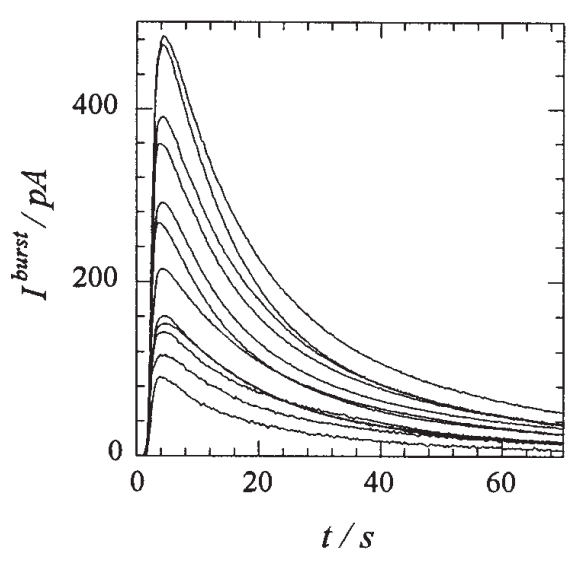

(a)

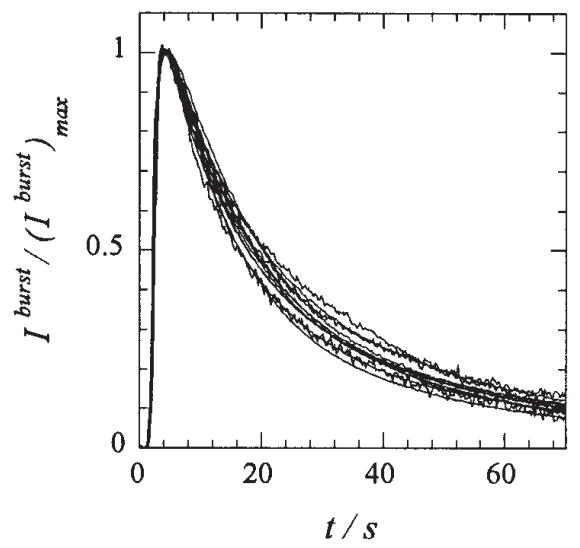

(b)

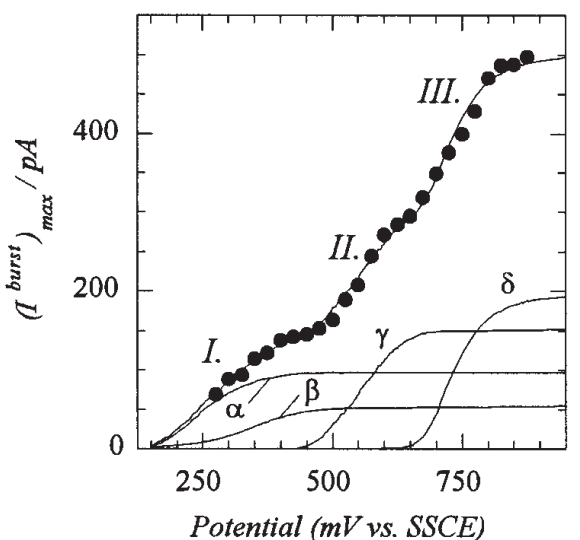

(c)

Figure 2. (a) Time dependence of the anodic currents monitored at different potentials after the stimulation of a human fibroblast by the micropipette, when the electrode ( $10 \mu \mathrm{m}$ radius) is positioned at $\boldsymbol{h}=\mathbf{5} \boldsymbol{\mu m}$ above the cell. From bottom to top : the electrode potential $E$ was varied from 300 to $850 \mathrm{mV}$ vs. SSCE by steps of $50 \mathrm{mV}$. Each curve represents the average of 25-40 individual events (see text). (b) Normalization of the traces shown in (a) relative to their individual maximum current value. (c) Variations of the maximum current intensity in (a) as a function of the electrode potential (solid symbols). This is compared to the voltammogram (solid curve) constructed by arithmetic addition of the individual voltammograms (noted $\alpha, \beta, \gamma, \delta$ and shown at bottom of the figure) obtained at the same electrode for $(\alpha) \mathrm{H}_{2} \mathrm{O}_{2} \quad\left(\begin{array}{lll}1.4 & \mu \mathrm{M}\end{array}\right)$, (b) $\mathrm{ONO}_{2}^{-}(1.7 \mu \mathrm{M}),(\gamma) \mathrm{NO}(19 \mu \mathrm{M})$ and $(\delta) \mathrm{NO}_{2}^{-}(4 \mu \mathrm{M})$ (see text). reproducible (i.e., culture-to-culture and day-to-day) and meaningful electrochemical data (i.e., with a $\pm 5 \%$ precision at $70 \%$ confidence, or $\pm 10 \%$ at $95 \%$ confidence) [35]. For example the set of data shown in figure $2 \mathrm{a}$ represents more than 500 individual experiments. All the data shown hereafter have been obtained through this long, fastidious, but necessary procedure.

Figure 2a [35] demonstrates the important variations of the oxidative stress amplitude in terms of the corresponding oxidation current, $I^{\text {burst }}$, as a function of the detection potential over the electrochemical window of interest. Interestingly, when these current traces are normalized to their current maxima, viz., upon plotting $I^{\text {burst }} /\left(I^{\text {burst }}\right)_{\max }$ as performed in figure $2 b$ [35], they almost superimpose, showing that their time course are extremely similar. In contradiction with this close time-behavior, plotting the current maxima, $\left(I^{\text {burst }}\right)_{\max }$, as a function of the detection potential (Fig. 2c [35]) demonstrates the presence of at least three different electrochemical waves (labeled $I$ to $I I I$ ).

The two more anodic waves are characteristic of $\mathrm{NO}$ (wave II: $E_{1 / 2}=0.555 \pm 0.005 \mathrm{~V} v s$. SSCE; one-electron oxidation) and $\mathrm{NO}_{2}^{-}$(wave III: $E_{1 / 2}=0.730 \pm 0.005 \mathrm{~V}$ vs. SSCE; two-electron oxidation) oxidations at our electrodes as demonstrated by their perfect matches to the steady state voltammograms of authentic bulk solutions of these species obtained under identical conditions (PBS solutions) at the same electrodes (voltammograms labeled $\gamma$ and $\delta$ in figure $2 \mathrm{c}$ for $[\mathrm{NO}]=19 \mu \mathrm{M}$ and $\left[\mathrm{NO}_{2}^{-}\right]=4 \mu \mathrm{M}$ respectively) [35,37] (vide infra).

The first oxidation wave $(I)$, with an apparent half-wave potential at $0.290 \pm 0.005 \mathrm{~V} v s$. SSCE, does not correspond to any expected ROS (vide supra), and moreover is considerably more sluggish than waves II and III. Furthermore, based on collection-efficiency measurements as a function of the cell-electrode distance [35,38], the diffusion coefficient relative to the species oxidized at this wave is comparable (i.e., ca., $2 \times 10^{-5} \mathrm{~cm}^{2} \mathrm{~s}^{-1}$ ) to that of $\mathrm{NO}_{2}^{-}$in the PBS extracellular fluid. This evidences that the molecule(s) giving rise to this oxidation wave is (are) comparable in terms of size (viz., molecular weight) and interactions with the PBS medium. This establishes that wave $I$ cannot feature at all the oxidation of proteins or larger biological molecules released by the cell through the puncture made in its membrane. Most of all, the time course of the released flux corresponding to this wave is extremely similar to those observed for $\mathrm{NO}$ and $\mathrm{NO}_{2}^{-}$(Fig. 2b). All these independent features strongly suggest that the species oxidized at wave $I$ is (are) closely related - chemically speaking - to NO and $\mathrm{NO}_{2}^{-}$, e.g., point out to the involvement of $\mathrm{ONO}_{2}^{-}, \mathrm{O}_{2}^{-}$or $\mathrm{H}_{2} \mathrm{O}_{2}$ (vide supra). However, at our electrodes, none of these species gives rise to authentic oxidation waves which could account alone for the oxidation wave $I$. The involvement of $\mathrm{O}_{2}^{-}$per se (sed vide infra) can be easily ruled out because wave $I$ is by far too anodic. In PBS, authentic samples of $\mathrm{ONO}_{2}{ }^{-}$and $\mathrm{H}_{2} \mathrm{O}_{2}$ are oxidized almost in the correct potential range at our platinized carbon electrodes, yet $\mathrm{H}_{2} \mathrm{O}_{2}$ $\left(E_{1 / 2}=0.250 \pm 0.005 \mathrm{~V}\right.$ vs. SSCE; two-electron wave $)$ gives 
rise to a slightly less anodic wave, while $\mathrm{ONO}_{2}^{-}$oxidation $\left(E_{1 / 2}=0.350 \pm 0.005 \mathrm{~V}\right.$ vs. SSCE; one-electron wave) is slightly more anodic as evidenced in figure $2 \mathrm{c}$ (voltammograms labeled $\alpha$ and $\beta$ obtained for $\left[\mathrm{H}_{2} \mathrm{O}_{2}\right]=1.4 \mu \mathrm{M}$ and $\left[\mathrm{ONO}_{2}^{-}\right]=1.7 \mu \mathrm{M}$ respectively).

Such close oxidation waves, i.e., with half-wave potentials located on each side of the experimental one $\left(E_{1 / 2}=0.290 \mathrm{~V} v s . \mathrm{SSCE}\right)$, in conjunction with the above results, strongly suggest that the sluggish oxidation wave at $E_{1 / 2}=0.290 \mathrm{~V} v s$. SSCE may actually not be a single wave but may result from the accidental superimposition of those of $\mathrm{H}_{2} \mathrm{O}_{2}$ and $\mathrm{ONO}_{2}^{-}$. To test for this hypothesis, we examined therefore if the in vivo oxidation current, $I^{\text {burst }}$, observed at wave $I$ (i.e., between 0.275 and $0.475 \mathrm{~V} v s$. SSCE; Fig. 2c, solid symbols) could be described as a linear combination of the oxidation currents $I^{\mathrm{H}_{2} \mathrm{O}_{2}}$ and $I^{\mathrm{ONO}_{2}}{ }^{-}$measured in vitro for authentic solutions of $\mathrm{H}_{2} \mathrm{O}_{2}$ and $\mathrm{ONO}_{2}^{-}$in $\mathrm{PBS}$ at the same electrodes (Fig. 2c, voltammograms labeled $\alpha$ and $\beta$ ). Thus, the experimental in vivo oxidation current was written as in eq. 13 [35]:

$$
I^{\text {burst }}=f \times\left[\varepsilon \times I^{\mathrm{H}_{2} \mathrm{O}_{2}}+(1-\varepsilon) \times I^{\mathrm{ONO}_{2}}\right]
$$

where $f$ is a scaling factor and $\varepsilon$ a weighting factor (note then that whenever eq. 13 applies, $1.5 \times f \varepsilon \mu \mathrm{M}$ and $1.5 \times f(1-\varepsilon) \mu \mathrm{M}$ represent the "equivalent" concentrations of $\mathrm{H}_{2} \mathrm{O}_{2}$ and $\mathrm{ONO}_{2}^{-}$detected at the maximum of the oxidative burst; sed vide infra for the real meaning of "equivalent" in this context). $f$ and $\varepsilon$ do not play the same role on the wave, so that they are independent parameters. Indeed, $\varepsilon$ affects the shape of the "reconstructed" wave, while $f$ only scales it in intensity. So, $\varepsilon$ was readily obtained through a linear correlation procedure by rewriting eq. 13 as:

$$
I^{\text {burst }} \propto\left[I^{\mathrm{ONO}_{2}^{-}}+\varepsilon \times\left(I^{\mathrm{H}_{2} \mathrm{O}_{2}}-I^{\mathrm{ONO}_{2}^{-}}\right)\right]
$$

since $I^{\mathrm{ONO}_{2}^{-}}$and $\left(I^{\mathrm{H}_{2} \mathrm{O}_{2}}-I^{\mathrm{ONO}_{2}}{ }^{-}\right)$have known values at each potential. This procedure gave $\varepsilon=0.45$ (correlation coefficient 0.994 , slope 2.10 , nine data points); $f=2.1$ was then obtained at once from the slope of the ensuing linear correlation [35]. This treatment led to an exact superimposition of the "reconstructed" voltammograms based on eq. 13 with $\varepsilon=0.45$ and $f=2.1$ [35]. Similarly, a "reconstructed" voltammogram based on a mixture of $\mathrm{H}_{2} \mathrm{O}_{2}(1.4 \mu \mathrm{M})$, $\mathrm{ONO}_{2}^{-}(1.7 \mu \mathrm{M})$, NO $(19 \mu \mathrm{M})$ and $\mathrm{NO}_{2}^{-}(4 \mu \mathrm{M})$, agrees excellently with the overall experimental voltammograms recorded during oxidative bursts (solid data points), as shown by the unlabelled solid line in figure $2 \mathrm{c}$.

Albeit the agreement is excellent, it must be stressed that the above attribution is based only on an electrochemical identity. However, other data based on enzymatic inhibitors or hydrogen peroxide scavengers will be reported in the following so as to definitively validate the above electrochemical result. Yet, we need first to establish other important features related to the oxidative burst composition and origin.

\section{Origin and quantification of the oxidative burst}

The ultramicroelectrode may detect only electroactive species which have flown away from the cell. The current responses shown in figure $2 \mathrm{a}$ reflect the exact time course of the fluxes of chemicals released by the cell since we checked (through flow injection experiments [33] or collector generator experiments [39]) that the time response of the electrode itself is faster than a few milliseconds. Similarly, variations of collection efficiency with the electrode-cell distance $[38,40]$ showed that all species detected have diffusion coefficients $D$ in the range of a few $10^{-5} \mathrm{~cm}^{2} \mathrm{~s}^{-1}$ [35]. Thus, when the electrode is positioned at $h=5 \mu \mathrm{m}$ from the cell as in figure 2, the diffusional time of flight $t_{\text {diff }} \approx h^{2} / D=25 \mathrm{~ms}[38,40]$, necessary for any chemicals released by the cell to reach the electrode surface, is negligible compared to any other time characteristic apparent in figure $2 \mathrm{a}, \mathrm{b}$. Both series of results demonstrate that the time course of the oxidation currents shown in figure $2 \mathrm{a}$ represents actually the time course of the fluxes of the different chemicals released by the cell after the fast depolarization of its membrane. However, at this stage, one does not know whether these chemicals are released through the punctured hole in its membrane, or through the membrane itself.

Cell cytosols may contain several enzymes which may be responsible for the generation of superoxide ion and nitrogen monoxide whose further spontaneous evolution or combination (vide supra) could easily account for the production of hydrogen peroxide, nitrogen monoxide, peroxynitrite, nitrite ions as determined electrochemically. If this is the case, in our experiments the oxidative burst would essentially appear as originating from the very narrow zone (of ca. $1 \mu \mathrm{m}$ radius) where the cell membrane has been pricked by the micropipette. Indeed, diffusion through the cell membrane is too slow to account for the magnitude of the fluxes detected here. The oxidative burst would then appear as a spherical diffusion wave emitted by the narrow damaged zone $[38,40]$.

However, such enzymes may also be present in cell membranes [41]. If enzymes effectively present in the cell membrane side exposed to the extracellular fluid are activated over a large surface area around the puncture, the oxidative burst should then appear as a planar diffusion wave emitted by a large area of the cell membrane [40].

The variation of the collection efficiency with the hole-electrode distance established that oxidative bursts mostly consist of a spherical diffusion wave emitted by the punctured hole [35], so that they mainly originate from the cell cytosol or from an extremely narrow zone (viz., with a radius less than 1-2 $\mu \mathrm{m}$ ) of its membrane located around the puncture. This is even more clearly demonstrated by experiments such as that shown in figure 3 [35]. In the previous experiments (Fig. 1, 2), the micropipette was immediately withdrawn after pricking the cell membrane. In the experiment shown in figure 3 , the micropipette was also withdrawn initially but it was then slithered back into the puncture so as to seal it (arrow marked A in Fig. 3) as soon as the current maximum was reached. This provoked an immediate and considerable drop of the current intensity. Withdrawing again the micropipette (arrow marked B in Fig. 3) unsealed again the punctured hole and restored the 


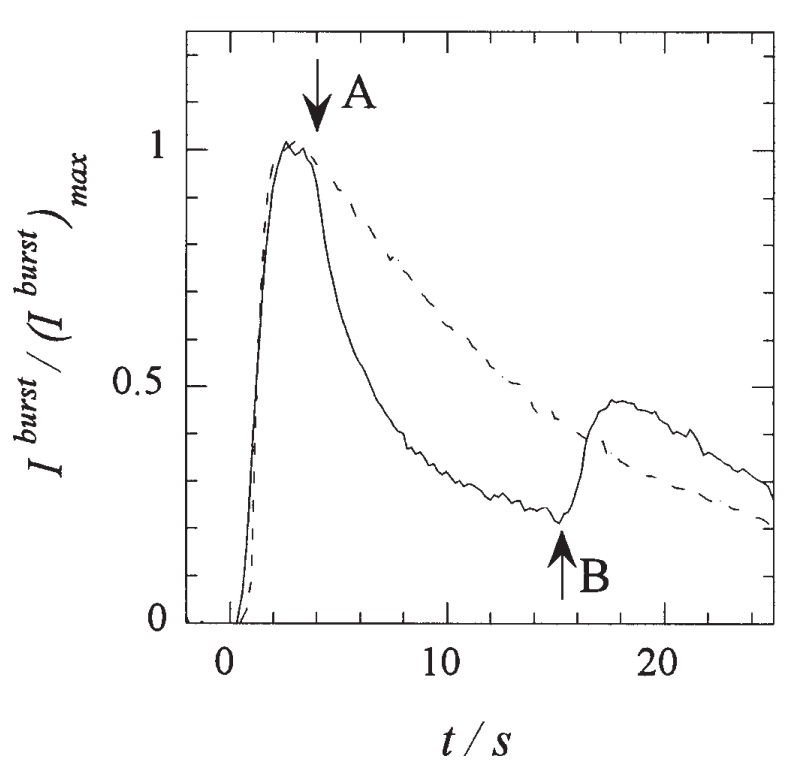

Figure 3. Variations of the current collected by the electrode ( $0.560 \mathrm{~V}$ vs. SSCE; $10 \mu \mathrm{m}$ radius, $h=5 \mu \mathrm{m}$ ) during an oxidative burst event when the micropipette is pushed back (arrow A, see text) into the membrane hole, or withdrawn again (arrow B, see text) ; dashed curve : control (compare Fig. 2a).

current at its former intensity, with even an overshoot corresponding presumably to the release of chemicals which had remained trapped within the cell cytosol when the punctured hole was closed. Such experiments demonstrate unambiguously that the oxidative burst fluxes mainly escape into the extracellular fluid by spherical diffusion through the punctured hole or are produced by the cell membrane within a narrow zone located around the puncture.

Besides its biological implications, the fact of knowing that the ROS are released through the membrane puncture has another important consequence. Indeed, when the electrode of $10 \mu \mathrm{m}$ diameter is placed above the punctured hole at a distance of $5 \mu \mathrm{m}$ (Fig. 1), its collection efficiency is nearly quantitative $[35,38,40]$. Therefore, the current intensities observed e.g. in figure 2 do not reflect at all classical electrochemical steady state currents [40], but represent the quantitative collection of the molecular fluxes $\Phi$ of chemicals emitted by the cell (viz., in moles per second), converted into currents through the Faraday's law by oxidation at the electrode surface [3-5]:

$$
I^{\text {burst }}=\Sigma\left(n_{j} F \times \Phi_{j}\right)
$$

where the summation encompasses all species $j$ oxidized at the collecting ultramicroelectrode through a process involving $n_{j}$ electron(s) per molecule at the potential under consideration. In particular, the diffusion coefficient of species $j$ plays no role (provided it is large enough to allow a $100 \%$ collection efficiency) in eq. 15. This is an extremely important notion since it allows to reconstruct the intensity and time-dependence of each flux $\Phi_{j}$ directly from the current traces in figure $2 \mathrm{a}$ without knowing a priori the diffusion coefficients and the local concentration gradients $[38,40]$. This brings us back to the very notion of "equivalent" concentrations given above, viz., $\mathrm{H}_{2} \mathrm{O}_{2}(1.4 \mu \mathrm{M}), \mathrm{ONO}_{2}-$ $(1.7 \mu \mathrm{M})$, NO $(19 \mu \mathrm{M})$ and $\mathrm{NO}_{2}^{-}(4 \mu \mathrm{M})$. Eq. 15 shows that these "equivalent" concentrations have no physicochemical meaning except that they are those required to produce an oxidation current (viz., depending on diffusion coefficients) in steady state voltammetry for each species which is similar to that detected by the collecting electrode when the oxidative burst intensity is maximum [35]. In fact, the effective concentrations ought to be much larger since in the present collection mode, only a limited fraction of the electrode surface area is exposed to the electroactive materials, while in the in vitro experiments, the whole surface is available to diffusion from the surrounding homogeneous solution (note that electrochemical currents are proportional to a concentration gradient times the electrode surface area exposed to this gradient; see ref. [35] for a discussion of this point). Furthermore, the geometry of the artificial synapse imposes concentration gradients which are steeper than the spontaneous ones which prevail in vitro at the same electrode [40], provided that the cell-electrode distance is smaller than the electrode radius as imposed here. Thus, it must be stressed that these "equivalent" concentrations must not be confused at all with any actual concentration of each species in the oxidative burst cocktail.

Based on eq. 15, and bearing in mind that the oxidation waves of $\mathrm{NO}$ and $\mathrm{ONO}_{2}^{-}$correspond to one-electron processes $\left(n_{j}=1\right)$, while those for $\mathrm{H}_{2} \mathrm{O}_{2}$ and $\mathrm{NO}_{2}^{-}$involve two electrons $\left(n_{j}=2\right)$, one may readily reconstruct the time course of the fluxes $\Phi$ of each species released during the oxidative burst. This is shown in figure $4 \mathrm{a}$, where the fluxes are represented in femtomoles per second. The time integration of these fluxes over the whole duration of the oxidative burst affords the overall quantity of each species released. It is then deduced that an average oxidative burst corresponds to the release within less than one minute $\left(t_{1 / 2} \sim 20 \mathrm{~s}\right)$ of a cocktail composed of $\mathrm{H}_{2} \mathrm{O}_{2}(15 \mathrm{fmol})$, $\mathrm{ONO}_{2}^{-}$(15 fmol), $\mathrm{NO}(30 \mathrm{fmol})$ and $\mathrm{NO}_{2}^{-}(15 \mathrm{fmol})$ [35].

\section{Central involvement of NADPH-oxidase and NO-synthase in the oxidative burst}

All the species identified above derive from the spontaneous evolution or cross-reactions of an initial tandem production of nitrogen monoxide and superoxide (eq. 1-11). Indeed, $\mathrm{H}_{2} \mathrm{O}_{2}$ results from the spontaneous evolution of superoxide ( $2 \mathrm{O}_{2}^{-}$per $\mathrm{H}_{2} \mathrm{O}_{2}$ detected, eq. 2-5); similarly peroxynitrite is formed by the diffusion limited coupling of $\mathrm{NO}$ and $\mathrm{O}_{2}^{-}$ ( $1 \mathrm{O}_{2}^{-}$and $1 \mathrm{NO}$ per $\mathrm{ONO}_{2}^{-}$detected, eq. 7); $\mathrm{NO}_{2}^{-}$results from the spontaneous decomposition of $\mathrm{ONO}_{2}^{-}$ (eq. 8,10,11 [26]) and represents therefore $1 \mathrm{O}_{2}^{-}$and $1 \mathrm{NO}$ per $\mathrm{NO}_{2}^{-}$detected. Therefore, the above individual quantities of each species feature in fact the release of equimolar amounts of superoxide and nitrogen monoxide by the cell (viz., 60 femtomoles of each). Note that this evaluation does not take into account that peroxynitrite may also evolve into nitrate ions (eq. 8,9 [26]) which cannot be detected under 


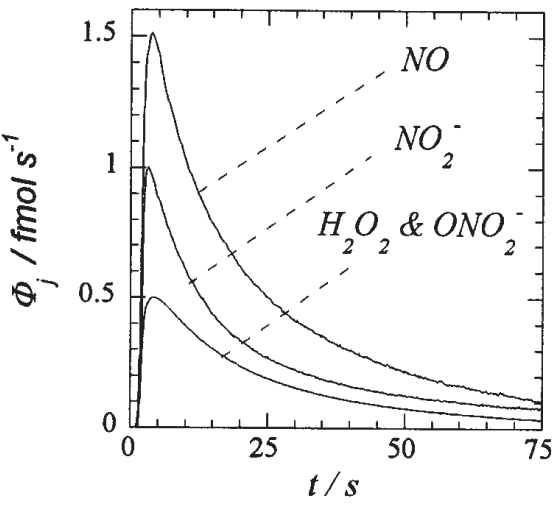

(a)
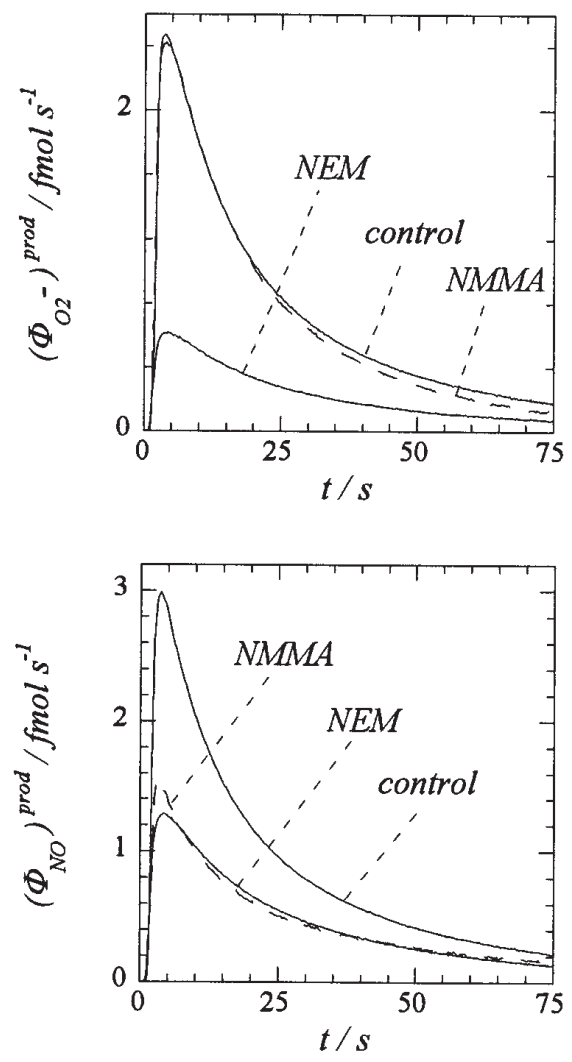

(c)

Figure 4. (a) Time variations of the individual fluxes (eq. 15) determined for each species (as indicated) present in oxidative bursts (note that the fluxes of hydrogen peroxide and peroxynitrite coincide). Each curve shown represents the average of 30 individual measurements. $(b, c)$ Control : time variations of the individual fluxes of the superoxide (b) and nitrogen monoxide (c) production fluxes as obtained through application of eqns. 16 (b) or 17 (c) to the data shown in (a). Curves labeled NEM or NMMA in $(b, c)$ are obtained as the control ones, except that the cells were pre-incubated with either NEM or NMMA inhibitors as indicated (see text).

our conditions. However, the toll would then be identical for superoxide and nitrogen monoxide since formation of one nitrate ion involves a 1:1 stoichiometry of each species (eq. 7-9). Therefore, the above measurement (i.e., 60 fmol of each species $\mathrm{O}_{2}^{-}$and $\mathrm{NO}$ ) represents a minimal value and should be re-evaluated whenever the production of nitrate ions were significant. Yet, based on the reported apparent rate constant $\left(0.2 \mathrm{~s}^{-1}\right.$ [26]) for the formation of nitrate ion from peroxynitrite, the half-life of peroxynitrite for this process is $c a$. one second. This is an excessively long duration compared with the extremely short duration $(25 \mathrm{~ms}$, vide supra) of the peroxynitrite diffusional flight between the cell and the electrode surface. Therefore, under or present experimental conditions, it is reasonable to assume that no significant amounts of nitrate ions are formed in comparison to the large quantities of superoxide and nitrogen monoxide formed.

This result may appear surprising in view of the fact that we consider that about half of the initially formed peroxynitrite decomposes into nitrite before reaching the electrode surface. Indeed, under normal physiological conditions the pseudo-second-order process leading to nitrite ions is reported to be slightly slower than the pseudo-first-order process leading to the formation of nitrate ions [26]. We believe that this inversion of reactivity originates from the un-physiologically high concentrations of peroxynitrite generated during brief oxidative bursts. Indeed, near the punctured hole, these concentrations ought to be comprised between several tens of $\mu \mathrm{mol} / \mathrm{L}$ and a few tenths of $\mathrm{mmol} / \mathrm{L}$ to account for the intensity of the currents detected [35]. The concentration-favored pseudo-second-order process leading to nitrite formation may then well kinetically overrun the concentration-independent pseudo-first-order pathway leading to nitrate ions, and become sufficiently fast to decompose a significant fraction of the released peroxynitrite into nitrite during the diffusion flight to the electrode surface.

Based on the above, the time courses of the individual production fluxes of $\mathrm{NO}$ and $\mathrm{O}_{2}^{-}$can be deduced from those detected for their follow-up products (Fig. 4a), through the following equations (note that we suppose that $\mathrm{H}_{2} \mathrm{O}_{2}$ results exclusively from superoxide dismutation and is not produced directly from dioxygen two-electron reduction):

$$
\begin{gathered}
\left(\Phi_{\mathrm{O}_{2}}\right)^{\text {prod }}=2\left(\Phi_{\mathrm{H}_{2} \mathrm{O}_{2}}\right)^{\mathrm{mes}}+\left(\Phi_{\mathrm{ONO}_{2}}\right)^{\mathrm{mes}}+\left(\Phi_{\mathrm{NO}_{2}}\right)^{\mathrm{mes}} \\
\left(\Phi_{\mathrm{NO}}\right)^{\text {prod }}=\left(\Phi_{\mathrm{NO}}\right)^{\mathrm{mes}}+\left(\Phi_{\mathrm{ONO}_{2}{ }^{-}}\right)^{\mathrm{mes}}+\left(\Phi_{\mathrm{NO}_{2}}\right)^{\text {mes }}
\end{gathered}
$$

Figures $4 \mathrm{~b}, \mathrm{c}$ present the results of this analysis for superoxide and nitrogen monoxide respectively [36].

The simultaneous observation of peroxynitrite (plus that of nitrite ion, its decomposition product), $\mathrm{NO}$ and $\mathrm{H}_{2} \mathrm{O}_{2}$ is a proof that $\mathrm{NO}$ and $\mathrm{O}_{2}^{-}$are not produced at the same location within the cell. Indeed, since these species couple at the diffusion limit (eq. 7), if they were produced within the same locations (viz., by the same enzymatic pools or by separate pools located within nanometric distances), they would annihilate each other so that only peroxynitrite (and nitrite, its main decomposition product) could be released by the cell. The simultaneous observation of hydrogen peroxide (featuring the spontaneous evolution of $30 \mathrm{fmol}$ of $\mathrm{O}_{2}^{-}$) and nitrogen monoxide (30 fmol) in addition to $15 \mathrm{fmol}$ of $\mathrm{ONO}_{2}^{-}$(plus $15 \mathrm{fmol}$ of $\mathrm{NO}_{2}^{-}$) thus establishes that only 


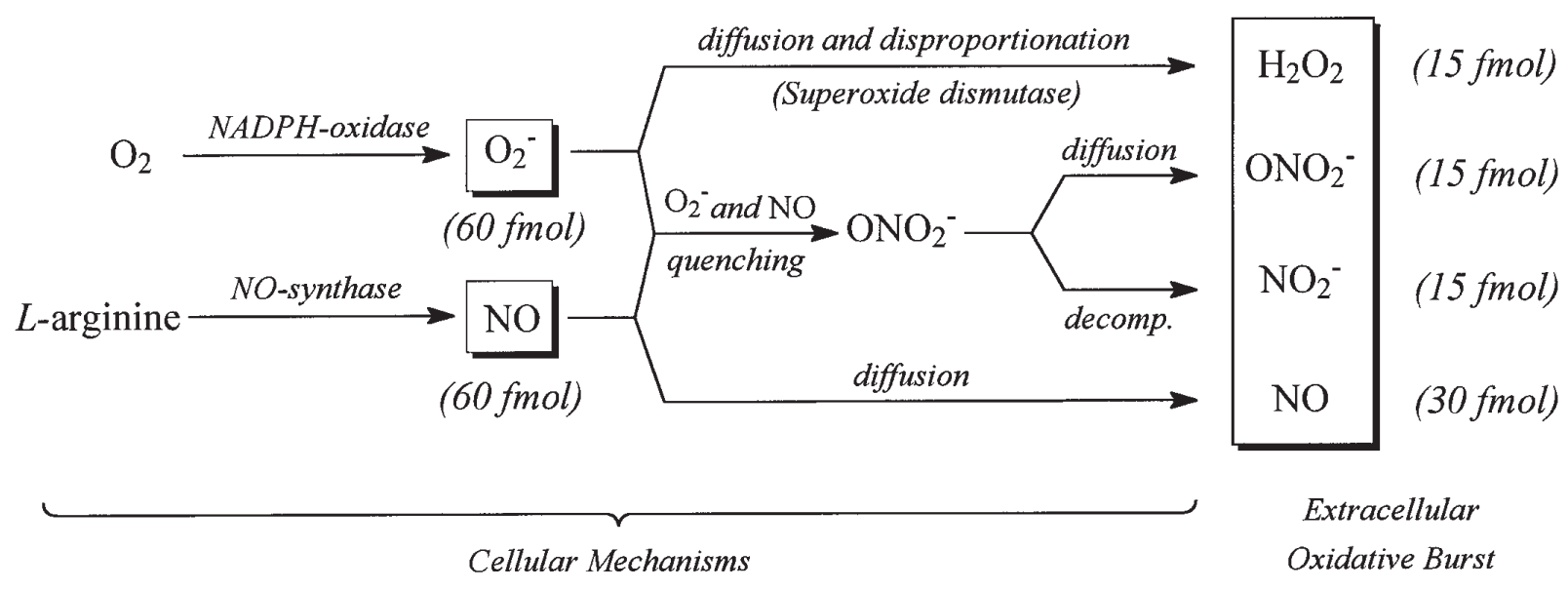

Scheme 1.

about half of the initially formed $\mathrm{O}_{2}{ }^{-}$and $\mathrm{NO}$ are allowed to react together.

This may occur only if they are formed in different locations separated by micrometric distances at least. Indeed, the $S O D$ catalyzed disproportionation of $\mathrm{O}_{2}^{-}$into $\mathrm{H}_{2} \mathrm{O}_{2}$ (eq. 5, $k^{\mathrm{SOD}}=2.5 \times 10^{9} \mathrm{M}^{-1} \mathrm{~s}^{-1}$ at $\mathrm{pH} 7$ [42]) occurs with a rate constant about ten times slower than that of its faster reaction with NO (eq. 7, $k^{\mathrm{NO}} \approx 2 \times 10^{10} \mathrm{M}^{-1} \mathrm{~s}^{-1}$ [26]). Thus, would an homogeneous situation prevail, $\mathrm{O}_{2}^{-}$disproportionation would be massively overrun by the faster coupling of $\mathrm{O}_{2}^{-}$and $\mathrm{NO}$ (eq. 7) whenever the fluxes of both species are similar as is observed here. More precisely, the relative yield in hydrogen peroxide would then represent $0.5 \times k^{\mathrm{SOD}} /\left(k^{\mathrm{SOD}}+k^{\mathrm{NO}}\right)$, i.e., less than $5 \%$ of the initially formed superoxide. NO being consumed stoichiometrically in eq. 7 , this would thus imply the release of less than $3 \mathrm{fmol}$ of $\mathrm{H}_{2} \mathrm{O}_{2}$ and $6 \mathrm{fmol}$ of $\mathrm{NO}$ at most, associated to more than 54 fmol for the sum of $\mathrm{ONO}_{2}^{-}$and nitrite ions. Such figures are clearly inconsistent with our observations.

Conversely, if both species are produced sufficiently far apart, two zones will be spontaneously created by means of diffusion $[43,44]$. One located around the $\mathrm{O}_{2}^{-}$source will contain almost no NO, the other centered around the NO source will contain almost no $\mathrm{O}_{2}^{-}$. The two species will annihilate each other at the interfacial boundary between these two diffusionally segregated zones. Under such conditions, a significant fraction of $\mathrm{O}_{2}^{-}$may disproportionate (eq. 5) into $\mathrm{H}_{2} \mathrm{O}_{2}$ while it diffuses to the interfacial boundary where the concentration of NO is high enough to impose mostly the formation of peroxynitrite. To precise this point, let us denote by $\delta$ the average distance between the superoxide and nitrogen monoxide sources inside the cell cytosol, so that the interfacial boundary is located approximately at $\delta / 2$ from the source of superoxide. Then, the diffusional time of $\mathrm{O}_{2}^{-}$ in the NO-free part of the cytosol is $c a$. $(\delta / 2)^{2} / D$ [40], where $D \approx 2 \times 10^{-5} \mathrm{~cm}^{2} \mathrm{~s}^{-1}$ is the local diffusion coefficient of $\mathrm{O}_{2}^{-}$. Denoting by $C^{0}$ the superoxide concentration at its source, a fraction $1 /(1+\rho)$, where $\rho=k^{\mathrm{SOD}} C^{0} \times \delta^{2} /(4 D)$, of the initial flux of superoxide would then be converted into $\mathrm{H}_{2} \mathrm{O}_{2}$ through its $S O D$-catalyzed disproportionation (eq. 5) before it may reach the boundary of the NO-rich zone where its remaining fraction will be almost exclusively converted into peroxynitrite (vide supra).

Experimentally, we observed that about half of the superoxide generated by the cell has disproportionated into $\mathrm{H}_{2} \mathrm{O}_{2}$, so that $\rho=k^{\mathrm{SOD}} C^{0} \times \delta^{2} /(4 D) \approx 1$. On the other hand, the dynamic concentration of $\mathrm{H}_{2} \mathrm{O}_{2}$ in the cytosol near the hole punctured in the membrane by the micropipette is ca. $15 \mu \mathrm{M}$ [35]. This corresponds to a would-be dynamic concentration of $c a .30 \mu \mathrm{M}$ of superoxide, and therefore to a superoxide concentration being double at its source (i.e., $C^{0} \approx 60 \mu \mathrm{M}$ ). Combining this series of data leads to an estimated distance between the $\mathrm{NO}$ and $\mathrm{O}_{2}^{-}$sources of approximately $\delta \approx 0.7 \mu \mathrm{m}$. Although one must keep in mind that this figure is necessarily approximate, its micrometric magnitude strongly suggests that the $\mathrm{NO}$ and $\mathrm{O}_{2}^{-}$sources are actually different and are located in different cellular compartments.

This points out to the simultaneous involvement of at least two different enzymatic pools, namely a NADPHoxidase-type pool as the main source of superoxide, and a NO-synthase pool as that of nitrogen monoxide. Therefore, the nature and composition of the oxidative burst cocktail released into the extracellular fluid through the puncture made into the cell membrane may be rationalized through the complex mechanism shown in scheme 1 .

\section{Effect of scavengers and enzymatic inhibitors on oxidative bursts}

All the above results have been inferred on the basis of electrochemical data only. Albeit the picture which emerges 
from these data is coherent electrochemically speaking or in view of previous biological or chemical knowledges, one cannot totally exclude that one of the electrochemical oxidation waves I-III observed in figure $2 \mathrm{c}$ has been unduly ascribed because of an accidental identity with the authentic oxidation wave of any of the four species identified (viz., $\mathrm{H}_{2} \mathrm{O}_{2}, \mathrm{ONO}_{2}^{-}$, $\mathrm{NO}$ and $\mathrm{NO}_{2}^{-}$). Indeed, if the electrochemical identification ought to be certain for $\mathrm{NO}$ and $\mathrm{NO}_{2}{ }^{-}$because these waves were well resolved and because their identification was based not only on $E_{1 / 2}$ values but on the whole wave, the decomposition of the sluggish oxidation wave $I$ (0.290 V vs. SSCE) into those of $\mathrm{H}_{2} \mathrm{O}_{2}$ and $\mathrm{ONO}_{2}^{-}$still remains more delicate, despite the excellent correlation obtained (Fig. 2c).

To support further our above interpretations, we thus wished to check the effect of specific scavengers or enzymatic inhibitors.

\section{Effect of catalase or activated cell peroxidases}

One of the crucial points in our above results concerns the presence of hydrogen peroxide in the oxidative burst. Catalase and cell peroxidases are scavengers of hydrogen peroxide, so the flux of this species ought to be drastically reduced whenever the surroundings of the cell are purposely enriched in catalase or in $o$-dianisidine (co-substrate of cell membrane peroxidases) prior to the stimulation of an oxidative burst. However, hydrogen peroxide represents only ca. $20 \%$ of the molar content of the oxidative burst under the conditions used here, so even a drastic decrease of its concentration would be difficult to observe, especially in view that the presence of catalase also decreases the electrode response by ca. $20 \%$ [33,37,39]. Furthermore, catalase is reported to be inhibited in the presence of important concentrations of NO [45]. This explains why we could not observe any significant decrease of the electrode oxidation current in the presence of catalase whenever the electrode was placed close to the cell $($ e.g., $h \approx 5 \mu \mathrm{m})$ [37,39].

These difficulties can nonetheless be by-passed by positioning the electrode at large distances from the cell surface (e.g., $h \approx 50 \mu \mathrm{m}$ [33]). Indeed, then $\mathrm{NO}$ and $\mathrm{ONO}_{2}^{-}$which are chemically unstable in the aerated extracellular fluid (vide supra) are expected to decay significantly during their seconds-long diffusional flights required to reach the electrode surface [40]. Conversely, in the absence of purposely added hydrogen peroxide scavengers, this species should survive the long diffusional flight. In complete agreement with this view, the oxidative burst signals measured at $0.560 \mathrm{~V} v$ s. SSCE (i.e., before the $\mathrm{NO}_{2}{ }^{-}$oxidation wave) and $h \approx 50 \mu \mathrm{m}$ [33] are smaller [35] than predicted on the basis of the reduced collection efficiency only $[38,40]$. This agrees with the expectations if one assumes that $\mathrm{NO}$ and $\mathrm{ONO}_{2}^{-}$do not survive their too long diffusional flights to the electrode surface under these circumstances $(h \approx 50 \mu \mathrm{m})$. Furthermore, when $h \approx 50 \mu \mathrm{m}$, the oxidative burst oxidation current measured at $0.560 \mathrm{~V} v s$. SSCE almost reduces to zero whenever the cell surroundings are purposely enriched with catalase or $o$-dianisidine [33], evidencing that hydrogen peroxide also cannot survive the long diffusional flight in the presence of these scavengers. Both series of experiments thus demonstrate unambiguously that hydrogen peroxide is an essential component of the oxidative burst. This in turn validates the presence of peroxynitrite since the existence of hydrogen peroxide amply justifies a posteriori the linear regression treatment performed to resolve oxidation wave $I$ in figure $2 \mathrm{c}$.

In this respect, we wish to take advantage of this review to rectify here a previous interpretation made in our first investigations of oxidative bursts [33], based on the above series of experiments. In those seminal experiments, because of experimental constraints the electrode-cell distance could not be less than $c a$. $50 \mu \mathrm{m}$, so that the above series of experiments led us to conclude correctly (but not accurately) that hydrogen peroxide was the essential component of oxidative bursts. Now, thanks to our present better instrumentation, the ultramicroelectrode can be positioned as close as $5 \mu \mathrm{m}$, though leaving enough room for the placement and manipulation of the micropipette. These improved experimental conditions allowed the collection of other important but transient species (viz., $\mathrm{NO}$ and $\mathrm{ONO}_{2}^{-}$) released during oxidative bursts before they may decompose significantly. Therefore, hydrogen peroxide which we reported unduly as being the major component of oxidative bursts [33] is shown now [35] to be released but only as one species among others.

\section{Effect of N-ethylmaleimide (NEM) [36]}

NEM is a denaturating inhibitor of NADPH-oxidase [46-48]. It is however non-specific of this enzyme since it acts by cross-linking neighboring $\mathrm{SH}$ bonds of the proteic enzymatic shells. Since NADPH-oxidase and NO-synthase are structurally related enzymes, $N E M$ is expected to be active on both enzymes, even if it is most frequently used to reduce NADPH-oxidase activity in living cells.

In agreement with these expectations, the released fluxes of each species were considerably diminished when the cells were pre-incubated with $N E M$ prior to the stimulation of oxidative bursts. The inhibiting effect on each enzyme is better appreciated upon examining the attenuations of superoxide (Fig. 4b) and nitrogen monoxide (Fig. 4c) production fluxes, as obtained through the application of eqns. 16 and 17, respectively, to the experimental released fluxes observed for $\mathrm{H}_{2} \mathrm{O}_{2}, \mathrm{NO}, \mathrm{ONO}_{2}^{-}$and $\mathrm{NO}_{2}^{-}$. These results show that the production of superoxide is reduced by ca. $70 \%$, while that of NO is reduced by only ca. $50 \%$.

This is thus in complete agreement with our above results and with the expectation that $N E M$ is more active on NADPH-oxidase. Furthermore, since different attenuations are observed for each species, these results bring additional evidence to the fact that two different enzymatic pools are involved. This is an interesting observation since NO-synthase may produce superoxide (i.e., as NADPH-oxidase) whenever its substrate, $L$-arginine, is not available [49]. 


\section{Effect of $\mathbf{N}^{\mathrm{G}}$-monomethyl-L-arginine (NMMA) [36]}

NMMA is a competitive inhibitor specific of NO-synthases [49], acting in competition with its substrate, $L$-arginine. To the best of our knowledge, there is no report that NMMA interacts with other enzymes. Therefore, cells pre-incubated with this inhibitor are expected to decrease appreciably their production of $\mathrm{NO}$, viz., to reduce significantly the detected fluxes of $\mathrm{NO}, \mathrm{ONO}_{2}^{-}$and $\mathrm{NO}_{2}^{-}$. Conversely, this inhibitor should not affect the production flux of superoxide, so that the flux of hydrogen peroxide should even increase since less $\mathrm{O}_{2}^{-}$should be quenched by NO.

This is effectively what is observed [36], the flux of hydrogen peroxide increasing by $c a .60 \%$, while those of $\mathrm{NO}, \mathrm{ONO}_{2}^{-}$and $\mathrm{NO}_{2}^{-}$were concomitantly reduced by ca. $50 \%$ (NO: $35 \%, \mathrm{ONO}_{2}^{-}: 50 \%$ and $\mathrm{NO}_{2}^{-}: 60 \%$ ). This is even more apparent when comparing the effect of NMMA on the production fluxes of $\mathrm{O}_{2}^{-}$(Fig. 4b) and NO (Fig. 4c). This set of figures demonstrate that the production flux of superoxide is absolutely not affected, while that of NO is reduced by $c a .50 \%$. Again, this establishes extremely firmly that two different and independent enzymatic systems are involved in the oxidative burst. In turn, this validates the major involvement of a NADPH-oxidase-like enzyme as the main source of superoxide, and therefore of hydrogen peroxide as one of the components of the oxidative burst. Finally, since the reduction in nitrite ion production $(60 \%)$ is comparable to those in NO and peroxynitrite, although being significantly larger, this validates also a posteriori our above interpretation that nitrite ions result from a secondorder decomposition of peroxynitrite (eq. 8,10,11 [26]).

\section{Conclusion}

This review demonstrates the great interest of artificial electrochemical synapses to identify and monitor the timedependent fluxes of extremely minute chemical quantities released by a living cell. Here, the method has been shown to lead to extremely important biological informations even in an extremely complex situation since several chemically interconnected species are released simultaneously by the cell, being also a challenging experimental situation because all the released molecules are extremely difficult to characterize electrochemically due to the intrinsic sluggishness of their oxidation waves and to the impossibility of using fast voltammetric techniques [2-5].

The existence of oxidative bursts involving complex ROS mixtures was postulated in biology as a pre-requisite for the observation of several metabolites and activation of various cellular biological mechanisms [28]. Only a few electrochemical studies examined the oxidative burst problem at the single cell level before, and to the best of our knowledge, only the release of superoxide ion has been reported $[48,50]$. Release of NO has been investigated electrochemically at the single cell level, but not under oxida- tive stress conditions [51]. The present series of investigations on fibroblasts establishes that these oxidative bursts are much more complex than previously assumed and that they occur within an extremely short time scale after a depolarization of the cell membrane.

They consist of a complex and concentrated cocktail of several important biological effectors: hydrogen peroxide, peroxynitrite and nitrogen monoxide, as well as of nitrite ions as a result from peroxynitrite decomposition at physiological $\mathrm{pH}$ under the un-physiological concentrated conditions which prevail during oxidative blasts. All these four species result from the tandem production of superoxide ion and nitrogen monoxide in almost equimolar amounts by two distinct enzymatic systems, NADPH-oxidase-type enzymes and NO-synthases, presumably located in different cellular compartments.

\section{Acknowledgements}

This work has been supported in part by CNRS, École Normale Supérieure and by the French Ministry of Research (MENESR). P.d.O. acknowledges an invited position fellowship from CNRS. We are also greatly indebted to UPR 42 (CNRS, Villejuif, France) and to its Director, Dr. Alain Sarasin, for providing the cell cultures used in this study.

\section{Experimental section}

All the relative experimental details as well as those concerning the electrode construction, electrochemical apparatus, PBS solutions or cell culture and handling are identical to those reported previously [33-35]. All the experiments were performed at $25{ }^{\circ} \mathrm{C}$ in Petri dishes placed on the stage of an inverted microscope. The electrode and micropipette were positioned with respect to each other and to the cell with two micromanipulators. The fibroblasts used in this study were obtained from a normal human cell line (198VI) established from a skin biopsy. They have been supplied to us by UPR 42 (CNRS, Villejuif).

In the experiments involving NEM (Sigma) the cells were pre-incubated for $10 \mathrm{~min}$ with $N E M, 30 \mu \mathrm{M}$, in PBS. For those involving NMMA (Sigma), the cells were pre-incubated for $3 \mathrm{~h}$ with $N M M A, 10 \mathrm{mM}$, in culture medium supplemented with $50 \mathrm{mM}$ HEPES buffer (Sigma). In both cases, at the end of the incubation period, the cells were washed three times with PBS and then analyzed in PBS.

\section{References}

1. For a recent review see: Wightman, R.M.; Runnels, P.; Troyer, K. Anal. Chim. Acta 1999, 400, 5.

2. For a review see: Clark, R.A.; Zerby, S.E.; Ewing, A.G. in Electroanalytical Chemistry; Bard, A.J.; Rubinstein, I. Eds., New York: Dekker, 1999, Vol. 20, pp 227-294. 
3. Amatore, C.; Bouret, Y.; Midrier, L. Chem. Eur. J. 1999, 5, 2151.

4. Amatore, C.; Bouret, Y.; Travis, E.R.; Wightman, R.M. Angew. Chem. Int. Ed. 2000, 39, 1952.

5. Amatore, C.; Bouret, Y.; Travis, E.R. ; Wightman, R.M. Biochim. 2000, 82, 481.

6. Amatore, C. C.R. Acad. Sci. Paris, Ser. II b 1996, 323, 757.

7. Hattori, R.; Sase, K.; Eizawa, H.; Kosuga, K.; Aoyama, T.; Inoue, R.; Sasayama, S.; Kawai, C.; Yui, Y. Int. J. of Cardiol. 1994, 47, S71.

8. Chance B.; William, G.R. J. Biol. Chem. 1955, 217, 409.

9. Chance, B. in Annual Review of Biophysics and Biophysical Chemistry; Engleman, D.M. Ed. Palo Alto: Annual Reviews, 1991, Vol. 20, pp 1-28.

10. Sies, H. in Metabolic Compartimentation; New York: Academic Press, 1982.

11. Denk, W.; Strickler, J.H.; Webb, W.W. Science 1990, $248,73$.

12. Zimmerman, R.; Cerutti, P.A. Proc. Natl. Acad. Sci. USA. 1984, 81, 2085

13. Cerutti, P.A. Science 1985, 227, 375.

14. Vuillaume, M. Mutat. Res. 1987, 189, 43.

15. Arnes, B.N. Free Radical Res. Commun. 1989, 7, 121.

16. Stadman, E.R. Science 1992, 257, 1220.

17. Molecular Biology of Free Radical Scavenging Systems Scandalios, J.S. Ed., Plainview, NY: Cold Spring Harbor Laboratory Press, 1992.

18. Arnes, B.N.; Shigenagra, M.K. Molecular Biology of Free Radical Scavenging Systems; Scandalios, J.S. Ed. Plainview, NY: Cold Spring Harbor Laboratory Press, 1992, pp 1-22.

19. Halliwell, B. Gutteridge, J.M.C. in Free Radicals in Biology and Medicine; Oxford; Clarendon Press, 1989.

20. Christman, M.F.; Morgan, R.W.; Jacobson, F.S.; Arnes, B.N. Cell 1985, 41, 735.

21. Darr, D.; Fridovich, I. Free Rad. Biol. Med. 1995, 18, 195.

22. Löntz, W.; Sirsjö, A.; Liu, W.; Lindberg, M.; Rollman, O.; Törmä, H. Free Rad. Biol. Med. 1995, 18, 349

23. Segal A.W.; Jones, O.T.G. Nature 1978, 276, 515.

24. Meier, B.; Cross, A.R.; Hancock, J.T.; Kaup; F.J.; Jones, O.T. Biochem. J. 1991, 275, 245.

25. Meier, B.; Jesaitis, A.; Emmendorffer, A.; Roesler, J.; Quinn, M.T. Biochem. J. 1993, 289, 481.

26. Kissner, R.; Nauser, T.; Brugnon, P.; Lye, P.G.; Koppenol, W.H. Chem. Res. Toxicol. 1997, 10, 1285

27. Ford, P.C.; Wink, D.A.; Stanbury, D.M. FEBS Lett. 1993, $326,1$.
28. For a survey and discussion of the relationship between $\mathrm{H}_{2} \mathrm{O}_{2}$ and apoptosis see: Torres-Roca, J.F.; Lecœur, H.; Amatore, C.; Gougeon, M.L. Cell Death Differ. 1995, 2, 309, and references therein.

29. Gougeon, M.L.; Olivier, R.; Garcia, S.; Guetard, D.; Dragic, T.; Dauguet, C.; Montagnier, L. C.R. Acad. Sci. Paris, Ser. III 1991, 312, 529.

30. Meyaard, L.; Otto, S.A.; Jonker, R.R.; Mijnster, M.J.; Keet, R.; Miedema, F. Science 1992, 257, 217.

31. Gougeon, M.L. Cell Death Differ. 1995, 2, 1.

32. Lachgar, A.; Sojic, N.; Arbault, S.; Bruce, D.; Sarasin, A. Amatore, C.; Bizzini, B.; Zagury, Vuillaume, M. J. Virology 1999, 73, 1447.

33. Arbault, S.; Pantano, P.; Jankowski, J.A.; Vuillaume, M.; Amatore. C. Anal. Chem. 1995, 67, 3382.

34. Arbault, S.; Edeas, M.; Legrand-Poëls, S.; Sojic, N.; Amatore, C.; Piette, J. Best-Belpomme, M. Lindenbaum, A.; Vuillaume, M. Biomed. Pharmacother. AIDS Sc. Sec. 1997, 51, 430.

35. Amatore, C.; Arbault, S.; Bruce, D.; de Oliveira, P.; Erard, M.; Vuillaume, M. Faraday Discuss. 2000, 116, in press.

36. Amatore, C.; Arbault, S.; de Oliveira, P.; Erard, M. unpublished results (2000).

37. Amatore, C.; Arbault, S.; Bruce, D.; de Oliveira, P. Erard, M. unpublished results (1999-2000).

38. Schroeder, T.J.; Jankowski, J.A.; Kawagoe, K.T.; Wightman, R.M.; Lefrou, C.; Amatore, C. Anal. Chem. 1992, 64, 3077.

39. Sojic, N. Ph.D. Thesis, University Paris 7, 1997.

40. Amatore, C. in Physical Electrochemistry: Principles, Methods and Applications, Rubinstein, I. Ed. New York: Dekker, 1995 pp 131-208.

41. Robinson, J.M.; Badwey, J.A. Histochem. 1995, 103, 163.

42. Koppenol, W.H. Free Rad. Biol. Med. 1998, 25, 385.

43. Amatore, C.; Brown. A. J. Am. Chem. Soc. 1996, 118, 1482.

44. Amatore, C.; Szunerits, S.; Thouin, L.; Warkocz, J.S. Electrochem. Commun. 2000, 2, 353.

45. Brown, G.C. Eur. J. Biochem. 1995, 232, 188.

46. Le Cabec, V.; Maridonneau-Parini, E. J. Biol. Chem. 1995 $270,10631$.

47. Yamashita, T.; Someya, A. Comp. Biochem. Physiol. 1987, $87 b, 969$.

48. Hill, H.A.O.; Tew, D.G.; Walton, N.J. FEBS Lett. 1985, 191 , 257.

49. Wang, R.; Ghahary, A.; Shem, Y.J.; Scott, P.G.; Tredget, E.E. J. Invest. Dermatol. 1996, 106, 419.

50. Isogai, Y.; Tsuyama, T.; Osada, H.; Lizuku, T.; Tanaka, K FEBS Lett. 1996, 380, 263.

51. Malinski, T. Taha, Z. Nature 1992, 358, 676 